\title{
Surface Roughness and Chip Morphology of Wood- plastic Composites Manufactured via High-speed Milling
}

\author{
Weihua Wei, ${ }^{\text {a } *}$ Rui Cong, ${ }^{\text {a }}$ Tongming Xue, ${ }^{\mathrm{a}}$ Ayodele Daniel Abraham, ${ }^{\mathrm{a}}$ and \\ Changyong Yang ${ }^{\mathrm{b}}$
}

\begin{abstract}
Wood-plastic composites have attracted extensive attention throughout the world because of their advantages. However, the manufacturing mechanism of the wood-plastic composites, i.e., high-speed milling technology, is not perfect and needs further study. The effects of the cutting parameters, i.e., the spindle speed, feed rate, axial milling depth, and radial milling depth, on the surface roughness and chip morphology were studied; the surface roughness values, $R_{\mathrm{a}}$ and $R_{\mathrm{z}}$ of high-speed milling wood-plastic composites samples were measured via high precision surface roughness measuring instrument, and their regression equations were calculated. The chips produced via a high-speed milling process were collected and studied. The results showed that the surface roughness of the wood-plastic composites increases with an increase in the axial depth, feed rate, or radial depth, but decreases with an increase in the spindle speed. In addition, the axial milling depth, feed rate, and spindle speed had a significant effect on the morphology of the chips. However, the effect of the radial milling depth on the morphology of the chips was not obvious. The results can provide a scientific basis for the optimization of high-speed milling processing of wood-plastic composites.
\end{abstract}

Keywords: Wood-plastic composites; High-speed milling; Surface roughness; Chip morphology

Contact information: a: College of Mechanical and Electrical Engineering, Nanjing Forestry University, Nanjing 210037 P. R. China; b: Jiangsu Key Laboratory of Precision and Micro-Manufacturing Technology, Nanjing University of Aeronautics and Astronautics, Nanjing, 210016 China., P. R. China;

*Corresponding author: whwei@njfu.edu.cn

\section{INTRODUCTION}

With the growth of population and the global demand for green energy, wood supply throughout the world is likely to face severe pressure in the coming decades (Chen et al. 2021a). Wood-plastic composites (WPCs) possess the combined advantages of wood and plastic; they not only have a natural wood-like appearance, but also have multiple advantages, e.g., they are resistant to degradation, moisture-proof, insect-resistant, higher in dimensional stability, resistant to cracking, not susceptible to warping, etc. WPCs also have good thermoplastics processability, higher hardness than plastic, and could be wearresistant, and aging-resistant (Arnandha et al. 2017; Ayrilmis et al. 2017; Dias and Alvarez 2017; Wang et al. 2017). As an advanced manufacturing technology with the advantages of improving the production efficiency, reducing the cutting force, improving the machining precision and surface quality, and reducing the costs, high-speed cutting technology has been widely used in the cutting of wood-based materials (Guo et al. 2018). The chips produced during the cutting of WPCs include long continuous chips, short continuous chips, flake chips, and granule chips (Darmawan and Tanaka 2004; Guo et al. 2014). WPCs are anisotropic and heterogeneous, resulting in noticeable milling vibration 
and noise during high-speed milling, also posing a major difficulty in chip removal, and the production of a large amount of chip dust at high removal rates. It also leads to difficulty in guaranteeing the machining accuracy and surface quality, and deterioration of the processing environment (Kılıç et al. 2009). Some studies have been made on the highspeed milling of wood plastic composites. For example, the tangential and radial forces decrease as the spindle speed increases, while they increase as the feed rate and axial milling depth increase (Wei et al. 2019a). Abrasive wear and coating peel-off are a primary form of tool wear; tool wear increases as the axial milling depth, spindle speed, or radial milling depth increases, and decreases as the feed rate increases (Wei et al. 2019b). Surface roughness is an important factor that affects the properties of WPCs (Hutyrova et al. 2014). According to Gurau and Ayrilmis (2019), the surface roughness of WPCs is affected by the composition of the raw materials used for manufacturing. Pang et al. (2020) believed that cutting parameters are the main factors determining the surface morphology of the workpiece. When processing oak wood, Ugulino and Hernandez (2017) found that the feed speed was the most influential cutting parameter affecting the surface roughness, and the surface roughness increased with an increase in the feed speed. From the discussions above, the research on chip and surface roughness mainly has focused on metal and wood materials, while the research on high-speed milling WPCs is relatively less.

Summarizing the current research status, there are many studies on the high-speed milling of metal or metal-based materials all over the world, but few studies have considered the high-speed milling technology of WPC composites. Research on reducing the dust-like chips from the perspective of improving processing environment still has not been carried out and needs to be further studied. Surface roughness is one of the most important indicators of engineering materials, and the dust-like chips produced during processing have severe impacts on the environment. Therefore, measures should be taken to prevent such negative impacts. To study the effects of the cutting parameters, i.e., the spindle speed, feed rate, axial milling depth, and radial milling depth, on the surface roughness and chip morphology, the authors used a typical WPC as the test object and adopted a carbide cutting tool to perform a high-speed milling test in this paper, and the reasons for the changes on the machined surface roughness and chip morphology were summarized. The research results can provide a reference for the selection of cutting parameters in high-speed milling of WPCs, improve the quality of the machined surface and reduce the dust-like chips produced in the machining process, and these have important theoretical value, and engineering applicability.

\section{EXPERIMENTAL}

Several WPCs pieces, produced by Nanjing Dayuan Plastic Wood New Material Co. Ltd. (Nanjing, China), were used in this research. The general properties of the material are shown in Table 1.

Table 1. Properties of the WPC

\begin{tabular}{|c|c|c|c|c|}
\hline Size $(\mathrm{mm})$ & $\begin{array}{c}\text { Proportion } \\
\text { (mass \%) }\end{array}$ & Density $\left(\mathrm{g} / \mathrm{cm}^{3}\right)$ & $\begin{array}{c}\text { Flexural Modulus } \\
(\mathrm{MPa})\end{array}$ & $\begin{array}{c}\text { Shore Hardness } \\
(\mathrm{HD})\end{array}$ \\
\hline $322 \times 75 \times 40$ & $\begin{array}{c}\text { Wood flour: } 65 \\
\text { Polyethylene: } 25 \\
\text { Rest: } 10\end{array}$ & 1.19 & 28 & 58 \\
\hline
\end{tabular}

Wei et al. (2021). "Wood-plastic composite milling," BioResources 16(3), 5733-5745. 
Translatable carbide cutting tools, manufactured by Zhuzhou Diamond Cutting Tool Co. Ltd. (Zhuzhou, China), were used in this study. The arbor model was the EMP01020-G20-AP11-02, and the blades used were ordinary carbide blades (grade YD201). The size of the tool diameter was $20 \mathrm{~mm}$, the tool nose radius was $0.4 \mathrm{~mm}$, and the relief angle is $11^{\circ}$.

The experiments were carried out on a 5-axis machining center (UCP 800 Duro) produced by Mikron (Agno, Switzerland), with a maximum spindle speed of $20000 \mathrm{rpm}$.

In this paper, the authors primarily study the influence of four parameters, i.e., the spindle speed $(n)$, the feed rate $\left(V_{f}\right)$, the axial milling depth $\left(a_{p}\right)$, and the radial milling depth $\left(a_{e}\right)$, on surface roughness and chip morphology. A single-factor test method was used in this experiment. Here, a factor was changed while the other three factors remained unchanged to observe the changes in the surface roughness and chip morphology. The selected milling parameters are shown in Table 2.

Table 2. Cutting Parameters

\begin{tabular}{|c|c|c|c|}
\hline$n(\mathrm{rpm})$ & $V_{f}(\mathrm{~mm} / \mathrm{min})$ & $a_{p}(\mathrm{~mm})$ & $a_{e}(\mathrm{~mm})$ \\
\hline 8000 & 1000 & 2 & 5 \\
\hline 12000 & 3000 & 3 & 7.5 \\
\hline 16000 & 5000 & 4 & 10 \\
\hline
\end{tabular}

\section{RESULTS AND DISCUSSION}

\section{Test Study on the Surface Roughness}

Surface roughness evaluation standard and measuring instrument

Surface roughness is one of the key indicators used to measure the quality of machined surfaces (Davim et al. 2009; Aguilera 2011; Prakash et al. 2012; Hernandez et al. 2013; Chen et al. 2021b). When measuring and evaluating surface roughness, the length of the sampling and evaluation need to first be determined. According to the commonly used surface roughness evaluation requirements, the surface roughness after milling was tested and a sampling length $(L)$ of $2.5 \mathrm{~mm}$ and an assessment length $\left(L_{n}\right)$ of $5 L$ were calculated. This implies that an assessment length of $12.5 \mathrm{~mm}$ was determined according to the wood surface roughness measurement outlined by GB/T standard 7220 (2004).

The measuring instrument used in this study to determine surface roughness was the MarSurf PS1, produced by Mahr Co. (Esslingen, Germany). Its working principle is to use its original built-in drive components to directly measure the surface roughness. This does not need any manual settings and its range is from $-200 \mu \mathrm{m}$ to $+150 \mu \mathrm{m}$, with a maximum scanning distance of $17.5 \mathrm{~mm}$. The MarSurf PS1 is small and easy to use and is fully compliant with the geometrical product specifications standards outlined by DIN EN ISO standard 3274 (1996). In addition, the PHT probe is moved forward or backwards along with a special movable block that efficiently removes dust and grease.

\section{Surface roughness measurement results}

In this test, surface roughness was determined based on the results of a tool wear test, i.e., the roughness values $R_{\mathrm{a}}$ and $R_{\mathrm{z}}$ of the machined surfaces, which were measured after the same length of milling in each group. The surface roughness of the workpiece was 
analyzed under the same conditions. At the time of measurement, the tool wear was at the stable wear stage, and three effective points were selected at different positions on the surface of each workpiece material, taking the arithmetic mean of the three points as the final surface roughness measurement. The specific measurement results are shown in Table 3 and Table 4.

Table 3. $R_{a}$ Test Results

\begin{tabular}{|c|c|c|c|c|c|c|c|c|}
\hline \multirow{2}{*}{ Number } & \multirow{2}{*}{$n(\mathrm{rpm})$} & \multirow{2}{*}{$V_{f}(\mathrm{~mm} / \mathrm{min})$} & \multirow{2}{*}{$a_{p}(\mathrm{~mm})$} & \multirow{2}{*}{$a_{e}(\mathrm{~mm})$} & \multicolumn{3}{|c|}{$R_{a}(\mu \mathrm{m})$} & \multirow{2}{*}{$\bar{R}_{a}(\mu \mathrm{m})$} \\
\hline & & & & & 1 & 2 & 3 & \\
\hline 1 & 16000 & 3000 & 4 & 10 & 2.4 & 1.9 & 2.0 & 2.1 \\
\hline 2 & 16000 & 3000 & 3 & 10 & 1.8 & 1.8 & 2.0 & 1.8 \\
\hline 3 & 16000 & 3000 & 2 & 10 & 1.8 & 1.9 & 1.6 & 1.7 \\
\hline 4 & 16000 & 5000 & 4 & 10 & 2.0 & 2.4 & 2.5 & 2.3 \\
\hline 5 & 16000 & 1000 & 4 & 10 & 2.0 & 1.8 & 2.0 & 1.9 \\
\hline 6 & 12000 & 3000 & 4 & 10 & 2.5 & 2.7 & 2.2 & 2.5 \\
\hline 7 & 8000 & 3000 & 4 & 10 & 2.8 & 2.7 & 2.8 & 2.8 \\
\hline 8 & 16000 & 3000 & 4 & 5 & 1.5 & 1.4 & 1.3 & 1.4 \\
\hline 9 & 16000 & 3000 & 4 & 7.5 & 2.0 & 1.7 & 2.2 & 2.0 \\
\hline
\end{tabular}

Table 4. $R_{z}$ Test Results

\begin{tabular}{|c|c|c|c|c|c|c|c|c|}
\hline \multirow{2}{*}{ Number } & \multirow{2}{*}{$n(\mathrm{rpm})$} & \multirow{2}{*}{$V_{f}(\mathrm{~mm} / \mathrm{min})$} & \multirow{2}{*}{$a_{p}(\mathrm{~mm})$} & \multirow{2}{*}{$a_{e}(\mathrm{~mm})$} & \multicolumn{3}{|c|}{$R_{z}(\mu \mathrm{m})$} & \multirow{2}{*}{$\bar{R}_{z}(\mu \mathrm{m})$} \\
\hline 1 & & & & & 1 & 2 & 3 & \\
\hline 2 & 16000 & 3000 & 4 & 10 & 17.4 & 23.1 & 15.9 & 18.8 \\
\hline 3 & 16000 & 3000 & 3 & 10 & 15.8 & 14.8 & 18.2 & 16.3 \\
\hline 4 & 16000 & 3000 & 2 & 10 & 14.2 & 19.4 & 11.5 & 15.0 \\
\hline 5 & 16000 & 5000 & 4 & 10 & 19.3 & 22.9 & 19.7 & 20.6 \\
\hline 6 & 16000 & 1000 & 4 & 10 & 20.6 & 14.5 & 17.1 & 17.4 \\
\hline 7 & 12000 & 3000 & 4 & 10 & 23.4 & 19.2 & 21.3 & 21.3 \\
\hline 8 & 8000 & 3000 & 4 & 10 & 28.0 & 26.6 & 25.5 & 26.7 \\
\hline 9 & 16000 & 3000 & 4 & 5 & 14.1 & 13.5 & 15.0 & 14.2 \\
\hline
\end{tabular}

\section{Influence of the Milling Parameters on the Surface Roughness}

Influence of the axial milling depth on the surface roughness

In order to determine the influence of the axial milling depth, only the $a_{p}$ value was changed ( $2 \mathrm{~mm}, 3 \mathrm{~mm}$, or $4 \mathrm{~mm}$ ), while the other parameters were kept constant, i.e., the $n$ was $16000 \mathrm{rpm}$, the $V_{f}$ was $3000 \mathrm{~mm} / \mathrm{min}$, and the $a_{e}$ was $10 \mathrm{~mm}$. It was found that the surface roughness of the machined surface of the WPC workpiece increases as the $a_{p}$ was increased, while milling the same length, as shown in Figs. 1 and 2, respectively. This occurs since the total area of the milling increases as the axial milling depth increases, which results in greater deformation resistance and milling force. Generally speaking, an increase in the milling force causes more severe extrusion deformation between the chip and the rake face and results in greater wear of the rake face, which leads to an increase in surface roughness. 


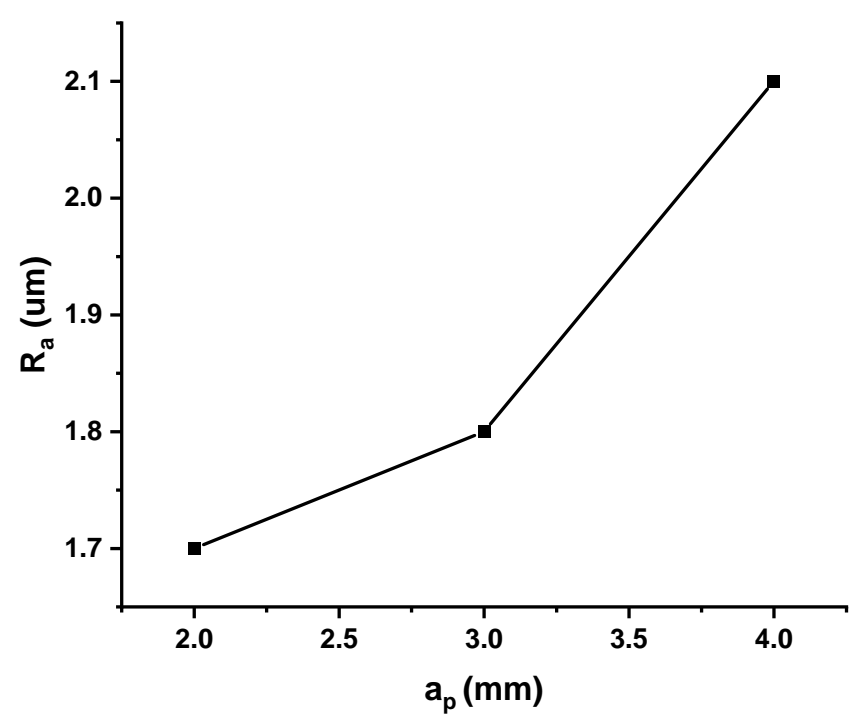

Fig. 1. The influence of the axial milling depth on the $R_{a}$

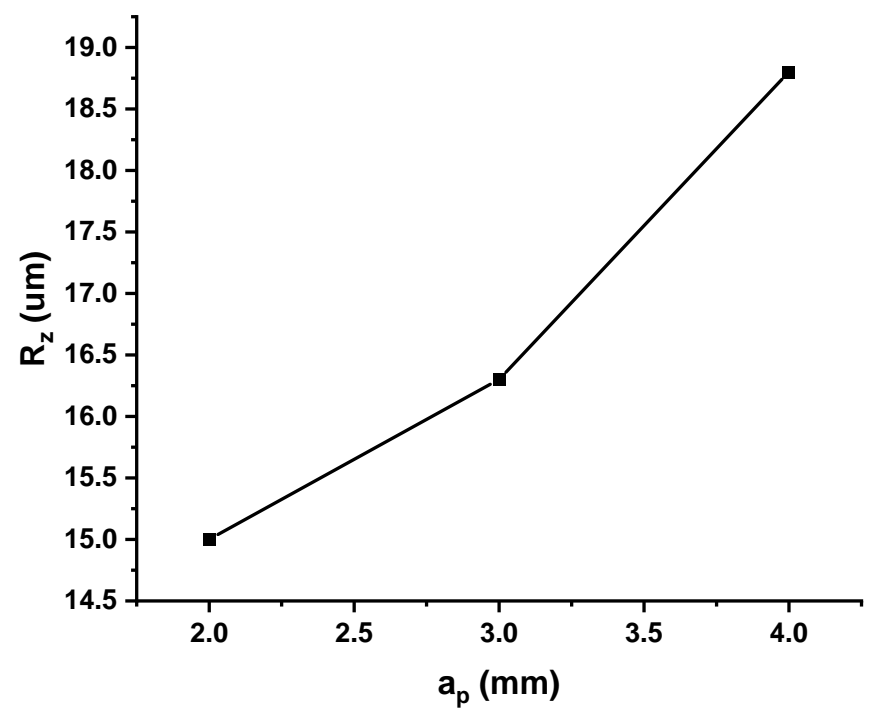

Fig. 2. The influence of the axial milling depth on the $R_{z}$

\section{Influence of the feed rate on the surface roughness}

In order to determine the influence of the feed rate, only the $V_{f}$ value was changed $(1000 \mathrm{~mm} / \mathrm{min}, 3000 \mathrm{~mm} / \mathrm{min}$, or $5000 \mathrm{~mm} / \mathrm{min})$, while the other parameters were kept constant, i.e., the $n$ was $16000 \mathrm{rpm}$, the $a_{p}$ was $4 \mathrm{~mm}$, and the $a_{e}$ was $10 \mathrm{~mm}$. It was found that the surface roughness of the machined surface of the WPC workpiece increased as the $V_{f}$ was increased, while milling the same length, as shown in Figs. 3 and 4, respectively. There are two reasons that can explain this finding: 1) an increase in the feed rate means that the tool will cut off more material in the same amount of time, i.e., the average milling depth increases. In this case the milling edge is subjected to a greater load and the vibration amplitude of the milling edge increases, which leads to an increased machined surface roughness; and 2) an increase in the feed rate means an increase in the feed per tooth, which is correlated with the depth and width of the ripple, resulting in a further increase in the surface roughness of the machined surface. 


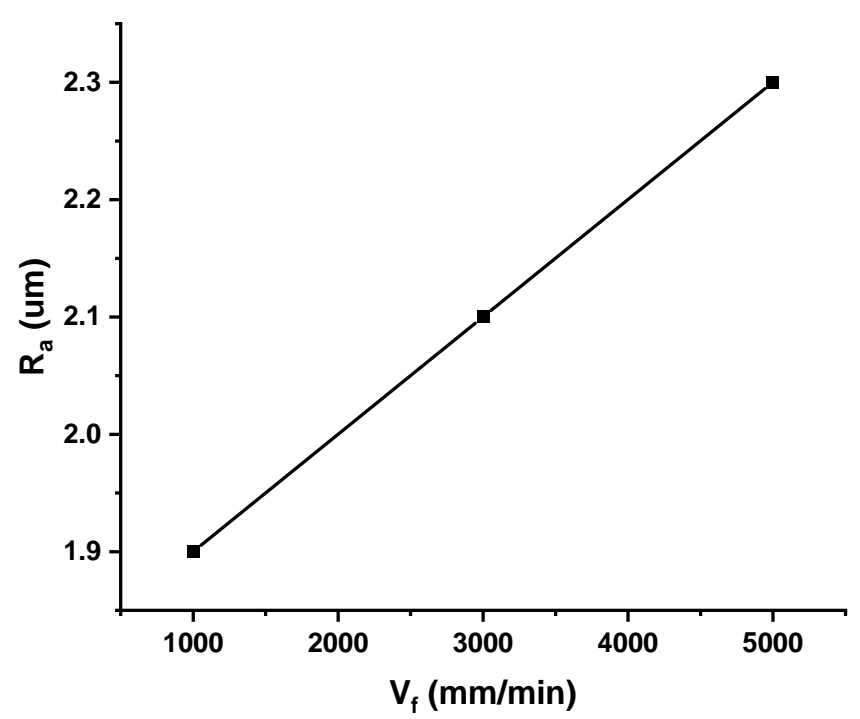

Fig. 3. The influence of the feed rate on the $R_{a}$

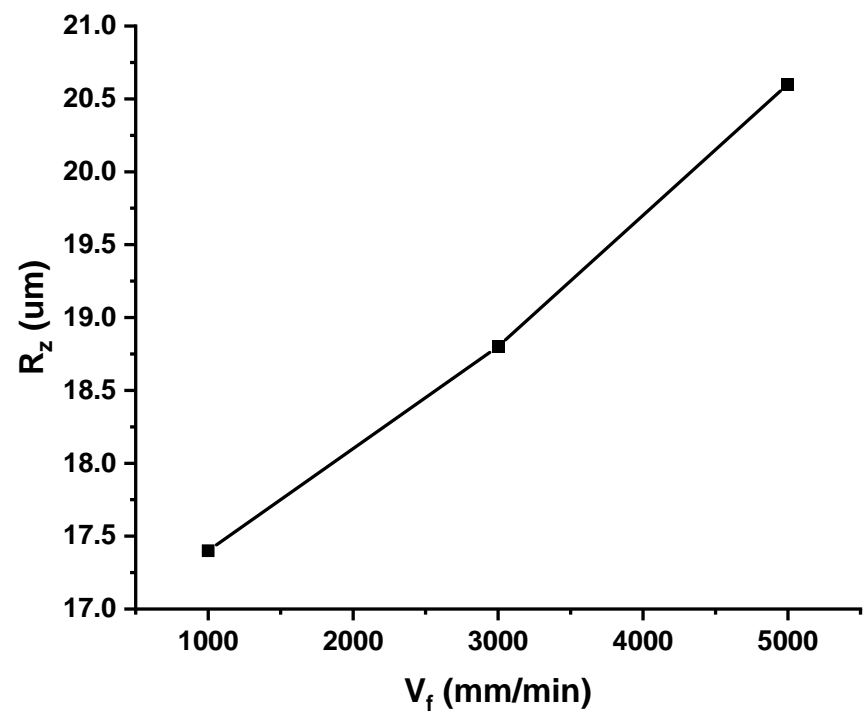

Fig. 4. The influence of the feed rate on the $R_{z}$

\section{Influence of the spindle speed on the surface roughness}

To determine the influence of the feed rate, only the $n$ value was changed ( 8000 $\mathrm{rpm}, 12000 \mathrm{rpm}$, or $16000 \mathrm{rpm}$ ), while the other parameters were kept constant, i.e., the $V_{f}$ was $3000 \mathrm{~mm} / \mathrm{min}$, the $a_{p}$ was $4 \mathrm{~mm}$, and the $a_{e}$ was $10 \mathrm{~mm}$. It was found that the surface roughness of the machined surface of the WPC workpiece decreased as the $n$ was increased, while milling the same length, as shown in Figs. 5 and 6, respectively. This happened because an increase in spindle speed reduces the single-time average milling amount, thereby decreasing the impact load, and reducing the milling edge of the load, thus decreasing the milling system vibration. As a result, machined surface roughness decreased significantly due to milling. The increase in spindle speed causes the tool nose to generate more cutting heat and the tool to thermally soften, which leads to a decrease in cutting force, cutting process stability, and surface roughness. 


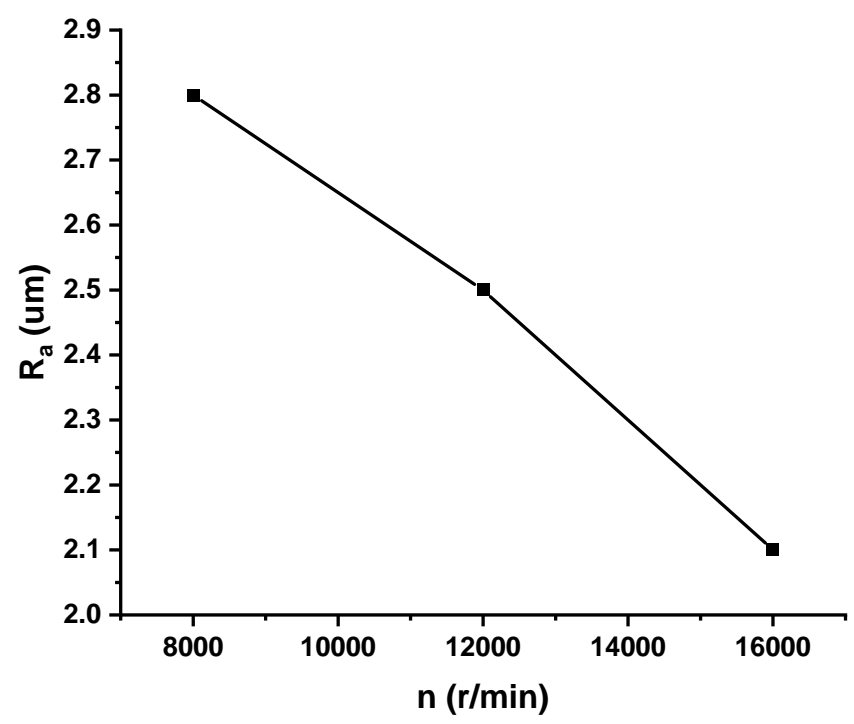

Fig. 5. The influence of the spindle speed on the $R_{a}$

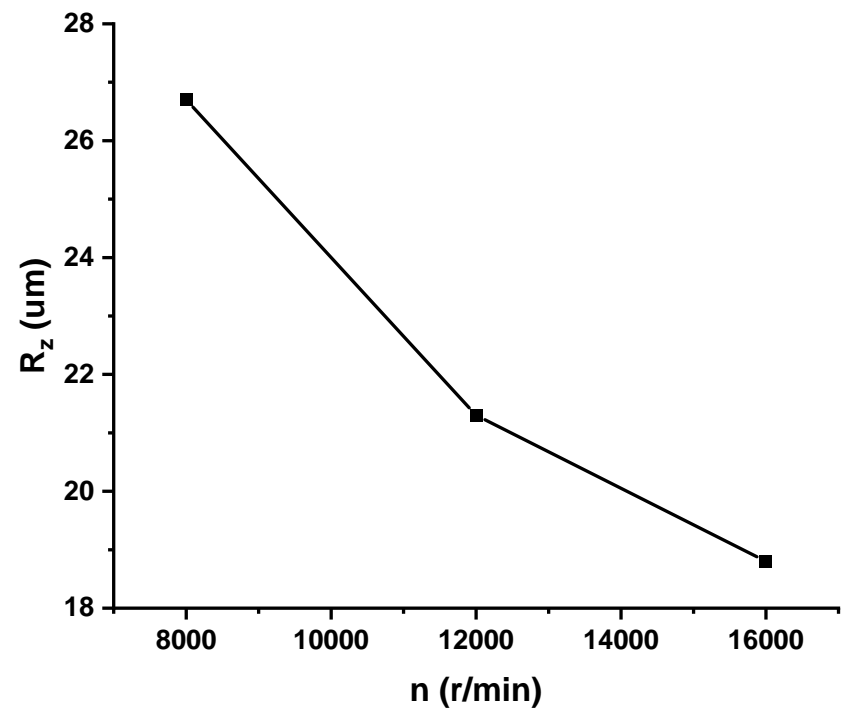

Fig. 6. The influence of the spindle speed on the $R_{z}$

Influence of the radial milling depth on the surface roughness

In order to determine the influence of the feed rate, only the $a_{e}$ value was changed ( $5 \mathrm{~mm}, 7.5 \mathrm{~mm}$, or $10 \mathrm{~mm}$ ), while the other parameters were kept constant, i.e., the $n$ was $16000 \mathrm{rpm}$, the $V_{f}$ was $3000 \mathrm{~mm} / \mathrm{min}$, and the $a_{p}$ was $4 \mathrm{~mm}$. It was found that the surface roughness of the machined surface of the WPC workpiece increases as the $a_{e}$ was increased, while milling the same length, as shown in Figs. 7 and 8, respectively. The primary reason for this is that, the cutting edge, while cutting one circle, will be exposed to more workpiece material as the radial depth increases. The impact load of the blade also increases, resulting in more obvious vibrations in the system, greater surface roughness, and longer friction time between the chip and the milling edge. 


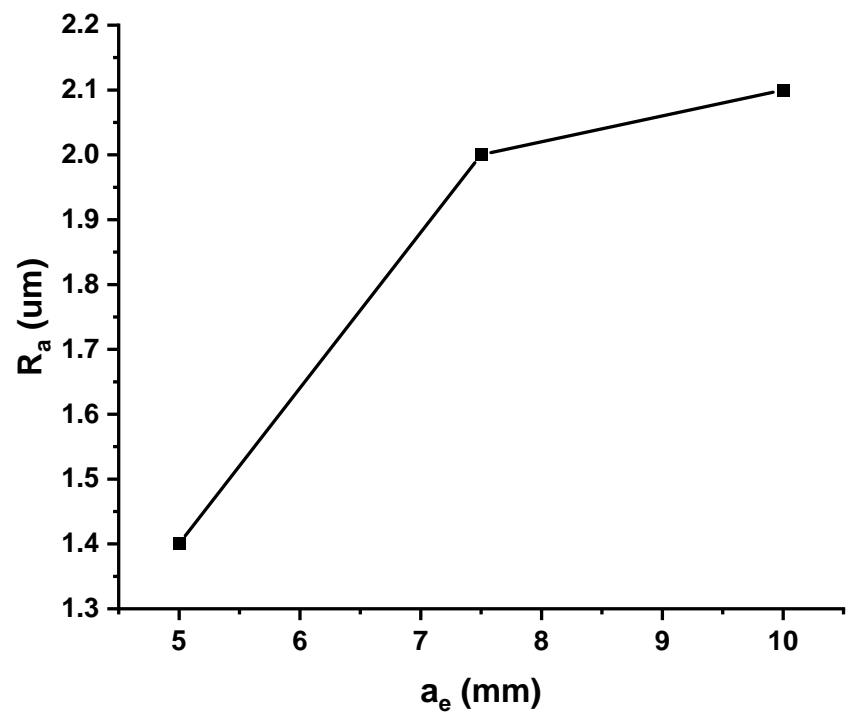

Fig. 7. The influence of the radial depth on the $R_{\mathrm{a}}$

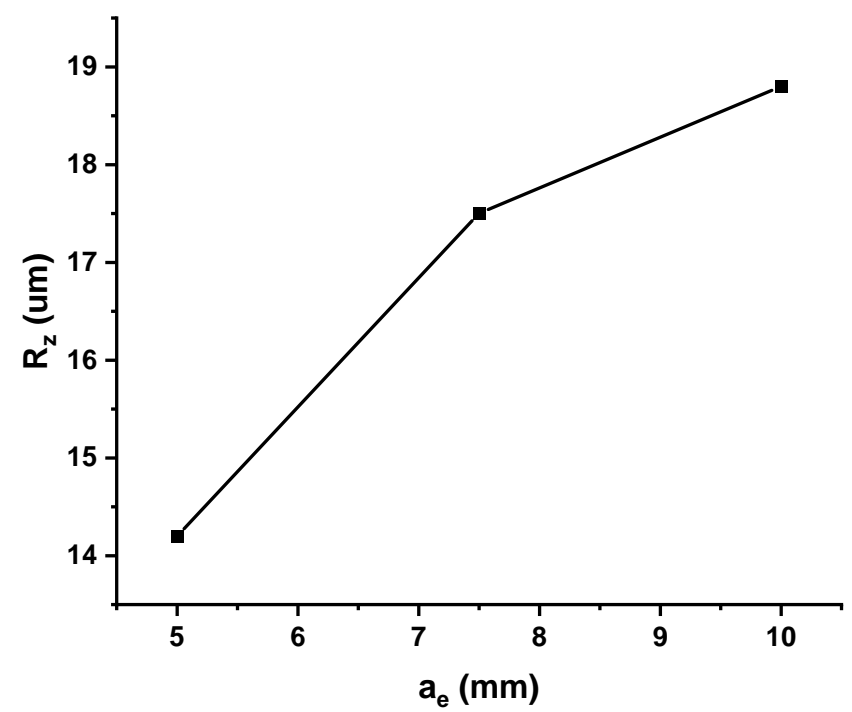

Fig. 8. The influence of the radial depth on the $R_{z}$

\section{Mathematical Model of the Surface Roughness}

Minitab statistical software was used to analyze the data in Tables 3 and 4. A stepwise regression analysis method was adopted to establish a mathematical fitting expression between the target response value and the independent variables, eliminating non-significant terms, and obtaining the quadratic polynomial regression equation, as shown in Eqs. 1 and 2:

$$
\begin{aligned}
& R_{a}=2.173-0.000079 n+0.00001 V_{f} a_{e}+0.02333 a_{p} a_{e} \\
& R_{z}=25.15-0.000959 n+0.1876 a_{p} a_{e}+0.000000134 V_{f}
\end{aligned}
$$

The significance analysis of the model was performed using analysis of variance (ANOVA) to test its feasibility. The p-value of $R_{\mathrm{a}}$ and $R_{\mathrm{z}}$ was 0.0005 and 0.0002 , respectively, which indicated that the established regression model was extremely 
significant (far less than 0.05). The $\mathrm{R}^{2}$ and the adjusted $\mathrm{R}^{2}$ of $R_{\mathrm{a}}$ were 0.9642 and 0.9427 , respectively. In addition, the $\mathrm{R}^{2}$ of $R_{\mathrm{z}}$ and the adjusted $\mathrm{R}^{2}$ of $R_{\mathrm{z}}$ were 0.9763 and 0.9621 , respectively, which indicated that the independent variables selected in the model can properly explain the dependent variables, demonstrate a great fitting effect, and provide a feasible established model.

\section{Analysis of the Chip Morphology}

In a machining process, the chip is produced by the extrusion of the material to be cut by the rake face of the cutting tool, which easily produces friction and impact on the rake face and cutting edge of the cutting tool. Cutting force fluctuates due to uneven cutting load in the process of chip formation. This has a negative effect on the quality of the machined surface, and the dust-like chips from the process also pollutes the environment (Calamaz et al. 2008; Upadhyay et al. 2012). It is therefore of importance to have an adequate understanding of this phenomenon in order to correctly select suitable cutting conditions. Wood chips can be divided into three types according to the size of the particles: dust-like chips, granular chips, and flake chips. Their morphologies are related to milling parameters in some way (K1liç et al. 2009). The following shows the reasons for the different chip morphologies. During the test, the chips were collected after milling and then collated, and the morphology of the chips produced via milling under each set of parameters was analyzed to determine the variations in chip morphology.

It is shown in Fig. 9 that almost all of the chip stack (Fig. 9a) consisted of flake chips, with only a few granular and dusty chips. The flake chips and granular chips coexist together (Fig. 9b). A few flake chips, and a lot of granular chips and dust-like chips are seen in Fig. 9c, as the shape of the flake chips, which were originally wide and short, gradually became narrower. This means that the chips are gradually smaller, and the particles are gradually thinner as the axial cutting depth decreases. The primary reason for this is that the WPC material is bound by a variety of wood or plant fibers and gelling agents. The WPC material has no strong binding force when the cutting thickness is small. The milling edge cuts the WPC material along the milling plane when the tool cuts into the WPC material. The shear force on the rake face is greater at this point. This causes the cutting layer of the material to easily produce broken deformations, forming small thin chips, granular chips, and dust-like chips. Hence, to reduce the formation of dust-like chips, a larger axial cutting depth should be selected.

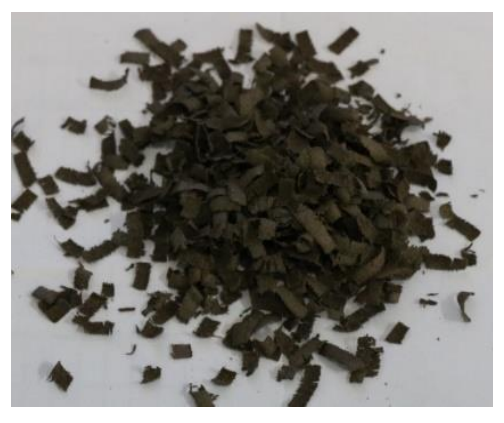

(a) $a_{p}=4 \mathrm{~mm}$

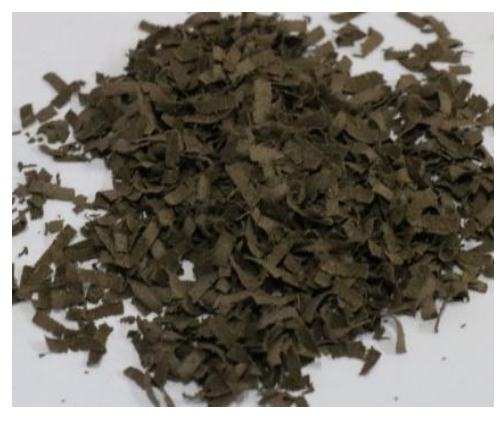

(b) $a_{p}=3 \mathrm{~mm}$

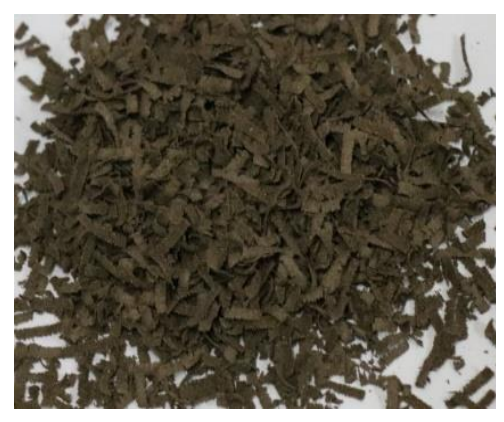

(c) $a_{p}=2 \mathrm{~mm}$

Fig. 9. The chip geometry when the axial milling depth was changed $\left(n=16000 \mathrm{r} / \mathrm{min}, V_{f}=3000\right.$ $\mathrm{mm} / \mathrm{min}$, and $a_{e}=10 \mathrm{~mm}$ ) 
The effect of the feed rate on the chip morphology is shown in Fig. 10. The chips shown in Fig. 10c are all wide and short, tending not to break. The chips in Fig. 10a are also wide and short, but a small amount of chips cracked into a narrow type. The chips in Fig. 10b are not just simple flake chips. Most of the chips in the chip stack are a small fibrous and granular type, and there are many smaller dust-like chips. It is shown that the chips gradually become smaller as the feed rate increases. The primary reason for this is that the larger feed rate increases the feed per tooth, i.e., the milling edge will yield bigger loads and vibration amplitudes, resulting in greater deformation of the chips. It will therefore be difficult for the chip to generate a stable form and will gradually rupture. Hence, to reduce the formation of dust-like chips, a smaller feed rate should be selected.

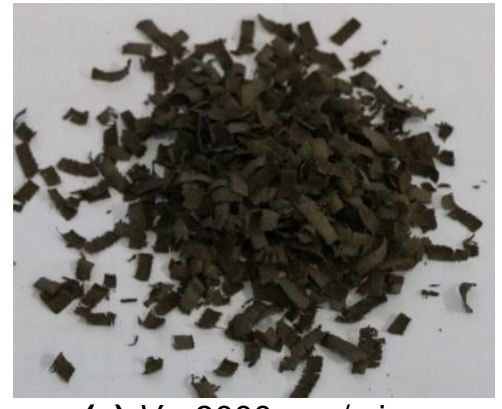

(a) $V_{f}=3000 \mathrm{~mm} / \mathrm{min}$

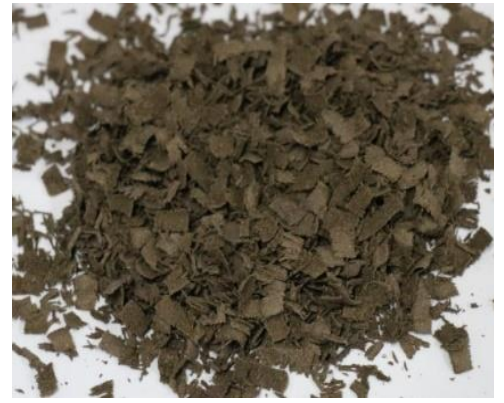

(b) $V_{f}=5000 \mathrm{~mm} / \mathrm{min}$

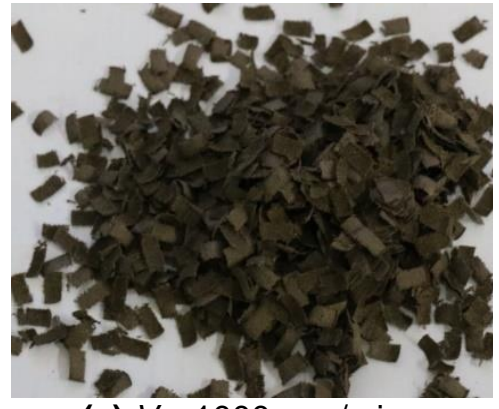

(c) $V_{f}=1000 \mathrm{~mm} / \mathrm{min}$

Fig. 10. The chip geometry when the feed rate was changed $\left(n=16000 \mathrm{r} / \mathrm{min}, a_{p}=4 \mathrm{~mm}\right.$, and $a_{e}$ $=10 \mathrm{~mm}$ )

Since the $V_{f}, a_{p}$, and $a_{e}$ are unchanged in Figs. 11a, 11b, and 11c, they reflect the effect of the spindle speed on the chip morphology. It can be seen that most of the chips in Fig. 11c are broken flake chips, some being microchips and others, granular chips. The chips in Fig. 11b are primarily flake chips, mixed with a small amount of micro-flake chips. In addition, some of the micro-flake chips are in a partially cracked state. The chips in Fig. 11a are almost flake chips; only a few chips are cracked. The reason for this change is that the increase in spindle speed reduces the feed per tooth, which decreases the average milling thickness and the milling force. This leads to a smaller impact on the chip, thus resulting in a more stable cutting force, and less deformation of the chips. Hence, to reduce the formation of dust-like chips, a larger spindle speed should be selected.

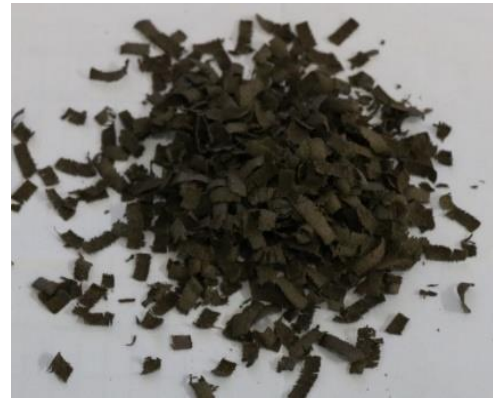

(a) $n=16000 \mathrm{rpm}$

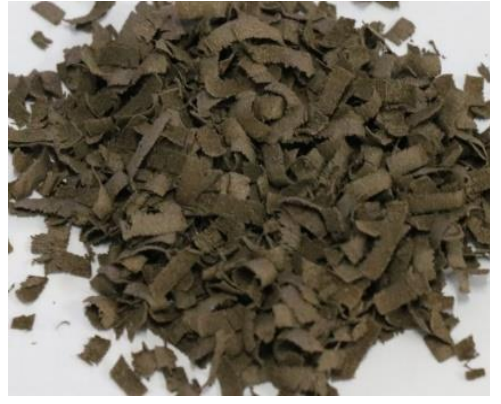

(b) $n=12000 \mathrm{rpm}$

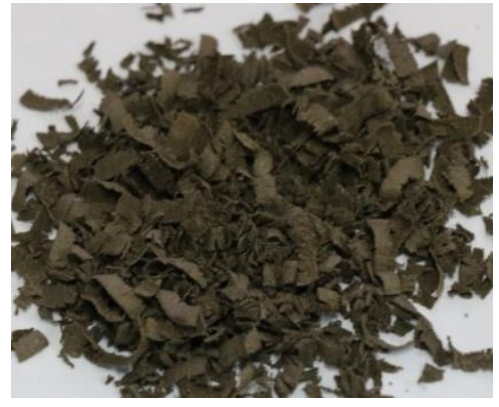

(c) $n=8000 \mathrm{rpm}$

Fig. 11. The chip geometry when the spindle speed was changed $\left(V_{f}=3000 \mathrm{~mm} / \mathrm{min}, a_{p}=4 \mathrm{~mm}\right.$, and $a_{e}=10 \mathrm{~mm}$ ) 
The values of $n, V_{f}$, and $a_{p}$, are unchanged in Figs. 12a, 12b, and 12c, reflecting the effect of the radial milling depth on the chip morphology. The chip morphologies shown in Figs. 12a, 12b, and 12c are almost identical; most of the chips are flake chips and only a few amount of the chips are cracked. It could therefore be concluded that the effect of the radial milling depth on the chip morphology is minute.

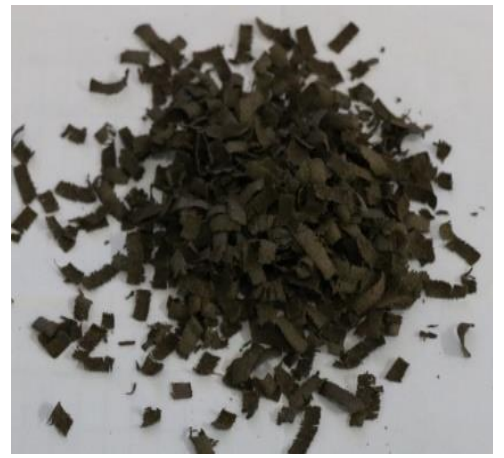

(a) $a_{e}=10 \mathrm{~mm}$

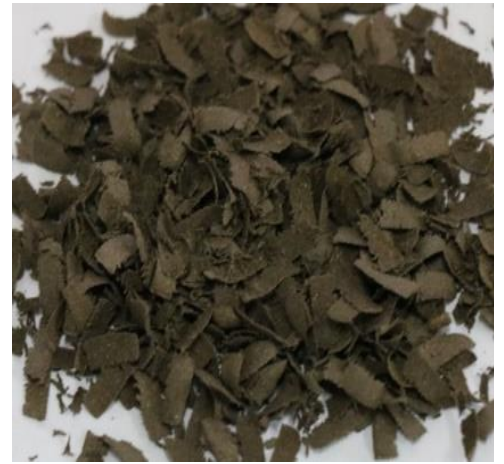

(b) $a_{e}=5 \mathrm{~mm}$

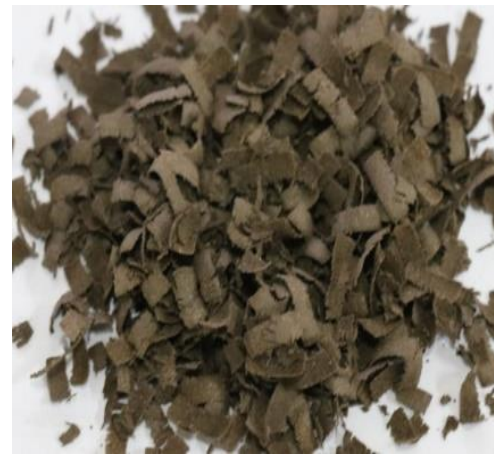

(c) $a_{e}=7.5 \mathrm{~mm}$

Fig. 12. The chip geometry when the radial depth was changed $\left(n=16000 \mathrm{rpm}, V_{f}=3000 \mathrm{~mm} / \mathrm{min}\right.$, and $a_{p}=4 \mathrm{~mm}$ )

\section{CONCLUSIONS}

1. High speed milling of wood-plastic composites (WPCs) was carried out based on single-factor experiment. The results showed that the machined surface roughness of the WPCs increases as the axial milling depth, feed rate, and radial milling depth increases. However, the surface roughness decreases as the spindle speed increases.

2. The stepwise regression analysis method was used to establish a mathematical fitting expression between the surface roughness and the milling parameters. The quadratic polynomial regression equations of surface roughness are as follows:

$$
\begin{aligned}
& R_{a}=2.173-0.000079 n+0.00001 V_{f} a_{e}+0.02333 a_{p} a_{e} \\
& R_{z}=25.15-0.000959 n+0.1876 a_{p} a_{e}+0.000000134 V_{f}
\end{aligned}
$$

3. Wood chips can be divided into three types according to the size of the particles: dustlike chips, granular chips, and flake chips. The axial milling depth, feed rate, and spindle speed had significant effects on the chip morphology, while the effect of the radial milling depth on the chip morphology was not obvious. A small axial milling depth and a large feed rate can cause greater deformation in the chips under high-speed milling conditions, which will make the chips break into smaller micro-flakes and particles. In addition, a greater spindle speed will cause more stable flake chips.

\section{ACKNOWLEDGEMENTS}

This research was financially supported by the Jiangsu Key Laboratory of Precision and Micro-Manufacturing Technology (2019), Jiangsu "Six Talent Peak" Project (JXQC022). 


\section{REFERENCES CITED}

Aguilera, A. (2011). "Surface roughness evaluation in medium density fibreboard ripsawing," European Journal of Wood and Wood Products 69(3), 489-493. DOI: 10.1007/s00107-010-0481-3

Arnandha, Y., Satyarno, I., Awaludin, A., Irawati, I. S., Prasetya, Y., Prayitno, D. A., Winata, D. C., Satrio, M. H., and Amalia, A. (2017). "Physical and mechanical properties of WPC board from sengon sawdust and recycled HDPE plastic," Procedia Engineering 171, 695-704. DOI: 10.1016/j.proeng.2017.01.412

Ayrilmis, N., Tasdemir, M., and Akbulut, T. (2017). "Water absorption and mechanical properties of PP/HIPS hybrid composites filled with wood flour," Polymer Composites 38(5), 863-869. DOI: 10.1002/pc.23647

Calamaz, M., Coupard, D., and Girot, F. (2008). "A new material model for 2D numerical simulation of serrated chip formation when machining titanium alloy Ti6Al-4V," International Journal of Machine Tools and Manufacture 48(3-4), 275-288. DOI: 10.1016/j.ijmachtools.2007.10.014

Chen, J., Guagliano, M., Shi, M., Jiang, X., and Zhou, H. (2021a). “A comprehensive overview of bamboo scrimber and its new development in China," European Journal of Wood and Wood Products 79(2), 363-379. DOI: 10.1007/s00107-020-01622-W

Chen, J., Zhang, L., Fu, Y., Qian, N., Jiang, H., and Yang, L. (2021b). "Heat transfer characteristics outside the condenser of a rotating heat pipe grinding wheel with a lateral air impinging jet," Journal of Thermal Science 30(2), 493-503. DOI: 10.1007/s11630-021-1415-6

Darmawan, W., and Tanaka, C. (2004). "Discrimination of coated carbide tools wear by the features extracted from parallel force and noise level," Annals of Forest Science 61(7), 731-736. DOI: 10.1051/forest:2004070

Davim, J. P., Clemente, V. C., and Silva, S. (2009). "Surface roughness aspects in milling MDF (medium density fibreboard)," International Journal of Advanced Manufacturing Technology 40(1-2), 49-55. DOI: 10.1007/s00170-007-1318-z

Dias, B. Z., and de Alvarez, C. E. (2017). "Mechanical properties: Wood lumber versus plasticlumber and thermoplastic composites," Ambiente Construído 17(2), 201-219. DOI: $10.1590 / \mathrm{s} 1678-86212017000200153$

GB/T 7220 (2004). “Geometrical product specifications(GPS)--Surface texture: Profile method-- Surface roughness--Terminology--Measurement of surface roughness parameters," Standardization Administration of China, Beijing, China.

Guo, X., Ekevad, M., Marklund, B., Li, R., Cao, P., and Grönlund, A. (2014). "Cutting forces and chip morphology during wood plastic composites orthogonal cutting," BioResources 9(2), 2090-2106. DOI: 10.15376/biores.9.2.2090-2106

Guo, X., Zhu, Z., Ekevad, M., Bao, X., and Cao, P. (2018). "The cutting performance of $\mathrm{Al}_{2} \mathrm{O}_{3}$ and $\mathrm{Si}_{3} \mathrm{~N}_{4}$ ceramic cutting tools in the milling plywood," Advances in Applied Ceramics 117(1), 16-22. DOI: 10.1080/17436753.2017.1368946

Gurau, L., and Ayrilmis, N. (2019). "Effect of raw material composition of wood plastic composites on surface roughness parameters evaluated with a robust filtering method," Journal of Thermoplastic Composite Materials 32(4), 427-441. DOI: 10.1177/0892705718759391

Hernández, R. E., Kuljich, S., Naffeti, O., and Koubaa, A. (2013). "Effect of the cutting speed on the surface quality of black spruce cants produced by a chipper-canter," Forest Products Journal 63(1-2), 39-46. DOI: 10.13073/fpj-d-13-00016 
Hutyrová, Z., Harničarová, M., Zajac, J., Valíček, J., and Mihok, J. (2013).

"Experimental study of surface roughness of wood plastic composites after turning," Advanced Materials Research 85(6), 108-112. DOI:

10.4028/www.scientific.net/AMR.856.108

ISO 3274 (1996). "Geometrical Product Specifications (GPS) — Surface texture: Profile method - Nominal characteristics of contact (stylus) instruments," International Organization for Standardization, Geneva, Switzerland.

Kiliç, M., Burdurlu, E., Aslan, S., Altun, S., and Tümerdem, O. (2009). "The effect of surface roughness on tensile strength of the medium density fiberboard (MDF) overlaid with polyvinyl chloride (PVC)," Materials \& Design 30(10), 4580-4583. DOI: 10.1016/j.matdes.2009.03.029

Pang, Q., Kuang, L., and Xu, Y. (2020). "The influence of cutting parameters on microtopography of frequency features extracted from the machined $\mathrm{KH}_{2} \mathrm{PO}_{4}$ surfaces," Proceedings of the Institution of Mechanical Engineers Part B: Journal of Engineering Manufacture 234(14), 1762-1770. DOI: 10.1177/0954405420927561

Prakash, S., Mercy, J. L., Palanikumar, K., Ramesh, S., Jamal, M. I. R., and Michael, A. J. (2012). "Experimental studies on surface roughness in drilling MDF composite panels using Taguchi and regression analysis method," Journal of Applied Sciences 12(10), 978-984. DOI: 10.3923/jas.2012.978.984

Ugulino, B., and Hernandez, R. E. (2017). "Assessment of surface properties and solventborne coating performance of red oak wood produced by peripheral planing," European Journal of Wood and Wood Products 75(4), 581-593. DOI: 10.1007/s00107-016-1090-6

Upadhyay, V., Jain, P. K., and Mehta, N. K. (2012). "Modelling and experimental study of chip serration frequency in dry turning of Ti-6Al-4V alloy," International Journal of Machining and Machinability of Materials 12(4), 358-371. DOI: 10.1504/IJMMM.2012.050434

Wang, L., Chen, S. S., Tsang, D. C. W., Poon, C. S., and Ok, Y. S. (2017). "Enhancing anti-microbial properties of wood-plastic composites produced from timber and plasticwastes," Environmental Science and Pollution Research 24(13), 12227-12237. DOI: $10.1007 / \mathrm{s} 11356-017-8770-6$

Wei, W., Li, Y., Xue, T., Liu, X., Chen, L., Wang, J., Wang, T., and Cai, Y. (2019a). "Research on milling forces during high-speed milling of wood-plastic composites," BioResources 14(1), 769-779. DOI: 10.15376/biores.14.1.769-779

Wei, W., Li, Y., Xue, T., Li, Y., Sun, P., Yang, B., Yin, Z., and Mei, C. (2019b). "Tool wear during high-speed milling of wood-plastic composites,” BioResources 14(4), 8678-8688. DOI: 10.15376/biores.14.4.8678-8688

Article submitted: March 19, 2021; Peer reviw completed: May 9, 2021; Revised version received and accepted: June 29, 2021; Published: July 1, 2021.

DOI: $10.15376 /$ biores.16.3.5733-5745 